\title{
Crimes contra a Humanidade, Justiça de Transição e Estado de Direito: Revisitando a Ditadura Brasileira.
}

\author{
Emilio Peluso Neder Meyer ${ }^{1}$
}

\section{Introdução}

Em 12 de dezembro de 2014, a Comissão Nacional da Verdade (CNV) publicou seu relatório final, trazendo inúmeros subsídios sobre a prática de graves violações de direitos humanos e crimes contra a humanidade no contexto da ditadura de 1964-1985. Houve clara recomendação no sentido de que as autoridades brasileiras não recorressem mais à Lei de Anistia de 1979 (Lei 6.683/1979) como artifício para obstaculizar as investigações e processos de agentes públicos pelo envolvimento em tais eventos. ${ }^{2}$ Mesmo não tendo havido consenso entre todos os comissionados, tendo José Paulo Cavalcanti Filho sido voto vencido, a CNV decidiu por categorizar os crimes da ditadura como crimes contra a humanidade, procurando evitar a incidência do argumento de que tais crimes seriam comuns e, portanto, estariam sujeitos à prescrição.

\footnotetext{
${ }^{1}$ Professor de Direito Constitucional na Faculdade de Direito da Universidade Federal de Minas Gerais (UFMG), Coordenador do Centro de Estudos sobre Justiça de Transição (http://cjt.ufmg.br). Mestre e Doutor em Direito pela UFMG. Pesquisador Visitante do Brazil Institute, King's College London (2014-1015). Esta pesquisa foi financiada pela CAPES - Coordenação de Aperfeiçoamento de Pessoal de Nível Superior (processo 3192-14-8).

2 "Para a fundamentação de sua posição, a CNV considerou que, desde meados do século XX, em decorrência da investigação e do julgamento de violações cometidas durante a Segunda Guerra Mundial, ocorreu a crescente internacionalização dos direitos humanos, com a consolidação de parâmetros de proteção mínimos voltados à proteção da dignidade humana. A jurisprudência e a doutrina internacionalista são unânimes em reconhecer que os crimes contra a humanidade constituem violação ao costume internacional e mesmo de tratados sobre direitos humanos. A elevada relevância do bem jurídico protegido - nas hipóteses de crimes contra a humanidade, a abranger as práticas de detenções ilegais e arbitrárias, tortura, execuções, desaparecimentos forçados e ocultação de cadáveres - requer dos Estados o cumprimento da obrigação jurídica de prevenir, investigar, processar, punir e reparar graves violações a direitos. A importância do bem protegido justifica o regime jurídico da imprescritibilidade dos crimes contra a humanidade e da impossibilidade de anistia, determinado pela ordem internacional e decorrente da proteção à dignidade da pessoa humana e da prevalência dos direitos humanos, previstas pela Constituição brasileira (artigos $1^{\circ}$, III, e $4^{\circ}, \mathrm{II}$ ), bem como da abertura desta ao direito internacional dos direitos humanos (artigo $5 \mathrm{o}$, parágrafos $2^{\circ} \mathrm{e}$ $3^{\circ}$ )" (Comissão Nacional da Verdade, 2014: 965).
}

3RASILIANA- Journal for Brazilian Studies. Vol. 4, n.1 (Aug. 2015). ISSN 2245-4373. 
Dentre tais crimes, o Relatório apresenta o caráter institucional e detalha as práticas de detenção (ou prisão) ilegal ou arbitrária, tortura, execução sumária, arbitrária ou extrajudicial, desaparecimento forçado e ocultação de cadáver.

Procuraremos demonstrar, no presente artigo, como o conceito de crimes contra a humanidade, recorrentemente utilizado pelo relatório da CNV, é consentâneo com a ordem jurídica brasileira. Ver-se-á que sua introdução para tratar dos crimes praticados por agentes públicos durante a ditadura não é lesiva ao princípio nullum crimen sine lege (ou seja, não há crime sem lei anterior que o defina), uma vez que sua aplicação decorre de uma normativa internacional já vigente, pelo menos, desde a Segunda Guerra Mundial. Tal normativa levaria à existência de um "Estado de Direito Humanitário" internacional que não poderia ter sido olvidado pelos agentes da ditadura.

Isto será feito mediante os seguintes passos: a) uma discussão e aproximação de um conceito de justiça de transição aberto a constantes reformulações; b) o significado do que se poderia chamar de um "Estado de Direito Humanitário"; c) como a normativa internacional absorveu o conceito de crimes contra a humanidade no chamado "Estado de Direito Humanitário"; d) como, recentemente, instituições no Brasil vêm paulatinamente incorporando a noção de crimes contra a humanidade, demonstrando como o relatório da $\mathrm{CNV}$, no que toca a esta recomendação, está em compasso com as demandas normativas da justiça de transição no Brasil.

\section{Justiça de Transição}

Em termos bastante didáticos, podemos verificar uma preocupação descritiva - como não poderia deixar de ser - na abordagem científica própria da Ciência Política responsável pela chamada "transitologia", que tinha por objeto, justamente, os 
momentos iniciais em que se abandona um Estado autoritário e se tenta passar a um regime democrático. É notável que essa literatura se veja obrigada a lidar com as incertezas que sempre permeiam as mudanças de regime e que, no momento de elaboração de tais teorias (final da década de 1970 e início da década de 1980), soarão como destaque dos fenômenos analisados.

Não é à toa que, no volume final da série de estudos empreendidos no projeto "Transitions from Authoritharian Rule: Prospects for Democracy in Latin America and Southern Europe" do Woodrow Wilson Center, os autores Guillermo O'Donnell e Philippe Schmitter introduzirão suas "tentativas de conclusão" com a palavra "incerteza". Ainda assim, a estrutura de tal incerteza irá conviver com conclusões parciais, quais sejam, a de que há um fim desejável, em todos os casos, de consolidação de uma democracia política, de que a teoria que estuda tais fenômenos tem que obrigatoriamente lidar com a indeterminação dos eventos envolvidos na transição e, por fim, de que é preciso lidar com uma "metodologia própria" para trabalhar com situações em constante fluxo político (O’Donnel e Schmitter: 1986, 3-4). Tais características, paradoxalmente, indicam a presença de padrões a respeito de situações que são, de fato, excepcionais.

Por isto, será possível para esse autores cunhar o sentido de termos que poderiam se deixar governar apenas pelas características de cada contexto político reduzido a determinado Estado. "Transição" será o intervalo entre um regime político e outro, qualquer que ele venha a ser; "consolidação" (com destaque para a consolidologia, um campo de estudos preocupado com o momento posterior à mudança), como o momento em que se verificam as condições do novo regime; "liberalização" como o processo de redefinir e estender direitos; "democratização" como o conjunto procedimental mínimo 
a abarcar elementos como voto secreto, sufrágio universal, eleições periódicas, liberdade de associação, legitimidade do Executivo e assim por diante.

A partir da leitura de vários e bastante diversos momentos transicionais ao redor do mundo, O’Donnell e Schmitter procuram desenhar estruturas que estão presentes em todos esses "locais". Ou seja, mesmo para quem se precaveu desde o início sobre (e não contra) a "incerteza", algum nível de definição se tornou possível - um nível que não encerraria, e não poderia pretendê-lo, o debate. Ainda assim, algo de normativo se perdeu. Alguma reflexão maior sobre o direito nas transições se fez ausente (Pinyo, 2013: 132; Quinalha, 2013). Tal ausência seria, de algum modo, preenchida anos mais tarde com os estudos que procuraram construir o que se chamou de justiça de transição.

Paige Arthur (2009: 31) destaca que a genealogia histórica do termo encontra menção histórica à expressão muito anterior aos debates que ocorreram nos anos de 1980 e $1990 .^{3}$ Ainda assim, uma reconstrução mais rigorosa exigiria uma metodologia que levasse em consideração, a partir da proposta de Quentin Skinner, o fato de que a invenção de novos termos no vocabulário político está articulada com respostas a problemas concretos. Não seria apenas a oportunidade, portanto, de Ruti Teitel ou de outros pesquisadores, que permitiria o surgimento da expressão - não obstante ela tenha sido decisiva na sua divulgação e implementação (Teitel, 2003). De modo semelhante, a publicação dos quatro volumes sobre a temática organizados por Neil Kritz (1995) mostrou-se fundamental para consolidação da expressão.

A persistência da expressão e sua aceitação de modo mais geral estava como que por detrás de tais publicações. Reivindicar transições para a democracia, ao invés de outros modelos políticos, econômicos ou sociais, deveu-se a alguns fatores: a) a reforma democrática tornou-se um dos objetivos de segmentos populacionais em diversos países

\footnotetext{
${ }^{3}$ A autora se refere à obra de Poldevaart (1948).
} 
que atravessavam mudanças políticas; b) a perda de legitimidade de antigas teorias da democratização associadas com teorias da modernização; c) a reabilitação do termo "transição", que é reconfigurado para além de uma perspectiva de transformação social para uma ótica de reforma no nível jurídico-institucional da política; e, d) poder-se-ia ainda pensar no destaque dado ao campo dos direitos humanos ao longo do final da década de 1970 por diversos atores sociais. Muitos deles, inclusive, diretamente engajados a partir da "sociedade civil" em uma ação de naming and shaming contra regimes autoritários em que graves violações de direitos humanos eram institucionalizadas. ${ }^{4}$

Ciente desses propósitos, seria possível para Arthur delinear, ao menos, uma base a partir da qual se possa pensar um conceito de justiça de transição: “[...] uma rede internacional de indivíduos e instituições cuja coerência interna é mantida por conceitos comuns, objetivos práticos e reivindicações próprias de legitimidade" ${ }^{5} \mathrm{~A}$ autonomia da justiça de transição, é preciso destacar com a autora, é construída a partir das conclusões de que esse campo: a) é passível de distinção do campo mais amplo dos direitos humanos do qual proveio; b) implica um conjunto de atores com finalidades comuns e orientados para uma ação recíproca; c) desenvolveu instituições que buscam alcançar tais finalidades; d) desenvolve critérios distintos de julgamento e auto-legitimação. Não será à toa, como se perceberá, que a autora utiliza o verbo no presente em relação à última conclusão: a justiça de transição não se furta a uma permanente reconstrução.

\footnotetext{
${ }^{4}$ Pense-se, por exemplo, no anterior Americas Watch (hoje Human Rights Watch), fundado no início da década de 1980 pelo exilado político argentino Juan Méndez - que viria, anos depois, a presidir a importante ONG International Center for Transitional Justice.

${ }^{5}$ Tradução livre de: "[...] an international web of individuals and institutions whose internal coherence is held together by common concepts, practical aims, and distinctive claims for legitimacy [...]" (Arthur, 2009: 324).
} 
Quando, em 1988, a diretoria do Programa para Justiça e Sociedade do Aspen Institute, exercida por Alice Henkin, vislumbrara a possibilidade de realização de uma conferência que pudesse discutir como países em transição para a democracia lidam com abusos do passado, a pergunta sobre os desafios políticos, morais e jurídicos da temática não conseguiria desviar dos elementos de responsabilizações individuais, acesso à verdade, reformas institucionais e reparações. É significativo o destaque dado por Arthur à conferência, já que a presença na mesma de um elenco plural de atores e pensadores como Lawrence Weschler, Ronald Dworkin, Thomas Nagel, Carlos Nino, Jaime Malamudi-Goti, Mahmood Mamdani, Diane Orentlicher, Paulo Sérgio Pinheiro, John Herz, Juan Méndez e José Zalaquett, entre outros, demonstraria a impossibilidade de um consenso sobre diversos dos temas relacionados, a não ser o acesso à verdade. Pois se a responsabilização de agentes dos aparatos repressores com base no Direito Internacional ainda demandaria maior debate no campo científico, a reconstrução de fatos ligados a abusos de direitos humanos deveria acontecer incondicionalmente (Arthur, 2009: 353).

Para além de tal debate, a própria conformação contextual da justiça de transição impulsionaria uma questionável dicotomia entre justiça e verdade ao longo da década de 1990. Mesmo os volumes editados por Neil Kritz parecem apontar, em 1996, nesse sentido. Por exemplo, Zalaquett destacara que, apesar de um acesso à verdade, como proclamação oficial e exposição pública, serem imperiosos, poderia ser o caso de, em certas circunstâncias, recorrer a clemência, com os possíveis e mesmos efeitos preventivos gerais de uma punição (Zalaquett in Kritz, 1995: 11). Detectando fatores como legados do autoritarismo, os termos da transição e o balanço de poderes entre civis e militares, Pion-Berlin irá destacar as circunstâncias da ação política pósautoritária como fundamentais para indicar ou não o caminho da justiça, deslocando a 
base normativa (Pion-Berlin in Kritz, 1995: 103). Naquilo que destaca como segunda fase da genealogia da justiça de transição, Teitel vê um destaque menor para instituições jurídico-políticas nesse momento, com o deslocamento do foco para atores não estatais e formas alternativas às cortes, como salas de depoimentos próprias para o testemunho discursivo. É o tempo das proliferação das comissões da verdade.

Não demorará muito para se noticiar que uma visão mais holística deverá imperar no processamento construtivo da justiça de transição. A justiça, que parecia ter cedido espaço para uma atuação exclusiva da verdade, volta a ser exigida, talvez pela peculiaridade dos crimes praticados em nome do Estado e contra a população peculiaridade esta que conforma a mesma justiça de transição em mais de um aspecto (Teitel, 2003, p. 86). Isto torna possível falar de uma justiça de transição que toca em aspectos significativos do Estado de Direito (rule of law): enquanto em democracias que contam com instituições mais amadurecidas, esse Estado de Direito é preocupado com o futuro apenas e contínuo em sua direção, no caso de momentos transicionais, ele é mais destacadamente preocupado com o passado e com o futuro, retrospectivo e prospectivo, contínuo e descontínuo, como ressaltará Teitel em 2001 (215).6 7

Por muito tempo, destacou-se que as medidas de justiça de transição variam de contexto para contexto e que, principalmente, a justiça poderia não se apresentar de imediato, devendo ser postergada em favor de outras ferramentas. "Assim, a ação

\footnotetext{
${ }^{6}$ Dificilmente tal constatação poderia ser mantida mesmo para o Direito em "situações de normalidade" (que já são, por si só, dificílimas de serem detectadas). É preciso interpretar a proposição da autora em seu contexto de construção do próprio conceito de justiça de transição.

${ }^{7}$ Não se ignora aqui a dificuldade de uma "tradução" do termo rule of law: ele possui diferentes implicações contextuais, como Estado de Direito, L'État de Droit ou Rechtstaat. Ainda assim, arriscaremos manter seu sentido como necessário para uma construção própria ao Direito Internacional dos Direitos Humanos. Para uma discussão sobre os diferentes sentidos, cf. Rosenfeld (2004).
} 
imediata em todos os aspectos da frente da justiça de transição não é sempre essencial". ${ }^{8}$ Mesmo assim, já em 2006, Roht-Arriaza chamava a atenção para o crescimento de uma superação de dualidades, em direção a uma ideia de justiça de transição "multifocada": “Duas dimensões - nacional/internacional ou comissão da verdade/julgamento - não são mais suficientes para mapear o universo dos esforços da justiça de transição". ${ }^{9}$

Será em meio a essas condições que Teitel falará de um constitucionalismo "construtivista" para a transição: “O constitucionalismo transicional não é apenas constituído pela ordem política prevalente, mas também é constitutivo da mudança política". ${ }^{10}$ A "constitutividade" do regime prevalente se apresentará com a memória não obrigada sobre aquele momento e com a negativa ostensiva das práticas que $o$ definiram. Só assim o momento constituinte pode ser visto como o de uma condição de possibilidade. Daí que apenas uma visão holística das ferramentas colocadas à disposição da justiça de transição pode dar conta de uma relação não excludente entre justiça de transição, constitucionalismo e Estado de Direito.

Caminhar em direção a tais ligações não é apenas uma exigência paroquial. Como destaca De Greiff, a experiência internacional demonstra que o apego a uma ou outra medida transicional, mesmo que de forma agressiva, pode soar muito mais como medida de conveniência do que de justiça. Exercícios de acesso à verdade, por exemplo, na Guatemala, acabaram por demonstrar que a questão não era apenas de se saber o que ocorrera, mas de agir contra o que se passou. Partindo da premissa de que, em regimes

\footnotetext{
${ }^{8}$ Tradução livre de: "Thus immediate action on all aspects of the transitional justice front is not always essential" (Lutz in Roht-Arriaza e Mariezcurrena, 2006: 334).

${ }^{9}$ Tradução livre de: "Two dimensions - national/international, or truth commission/trial - are no longer enough to map the universe of transitional justice efforts" (Roht-Arriaza in Roht-Arriaza e Mariezcurrena, 2006: 12).

${ }^{10}$ Tradução livre de: "Transitional constitutionalism not only is constituted by the prevailing political order but also is constitutive of political change" (Teitel: 2001: 191).
} 
de exceção, as normas mais fundamentais não são cumpridas, uma abordagem holística da justiça de transição tem a vantagem de demonstrar que há uma disposição mínima para garantir que aquelas normas voltarão ou começarão a ser cumpridas (De Greiff in Willians e Elster, 2012: 38-39).

O que se torna claro é que há uma compreensão abrangente do que significa a justiça de transição e essa compreensão está em permanente construção - até por que não se poderia desconsiderar uma compreensão interpretativa ou hermenêutica dessa expressão. Assim, há uma ênfase recorrente nos quatro tradicionais elementos da justiça de transição: responsabilização criminal individual; direito à memória e à verdade; reparações; e, reformas institucionais. Mas isto não significa que eles estejam imunes a reinterpretações.

Tais elementos estão em permanente construção e reconstrução, como "conceitos" a admitirem diferentes "concepções" fiéis ao postulado dos direitos humanos. ${ }^{11}$ Daí que as ferramentas da responsabilidade individual e do direito à memória e à verdade tenham, cada vez mais, indicado que dificilmente se estará dispondo adequadamente de uma justiça de transição sem problematizar os chamados "crimes contra a humanidade" e, principalmente, o modo como são eles investigados. Por isto é que, partindo da constatação de que há, de fato, uma autonomia da "justiça de transição", deve-se questionar qual a "elasticidade" desse conceito e como ele se relaciona com a normativa do Direito Internacional dos Direitos Humanos.

\footnotetext{
${ }^{11}$ A diferença entre "conceitos" e "concepções" está presente na obra de Dworkin e ganha maior densidade a partir da noção de que o Direito é formado por "conceitos interpretativos": "A diferença não diz respeito apenas ao grau de detalhe das instruções fornecidas, mas ao tipo de instruções. Quando recorro ao conceito de justiça, recorro ao significado do conceito de justiça, e não atribuo nenhuma importância especial a meus pontos de vista sobre a questão. Quando formulo uma concepção de justiça, defino um sentido para o conceito de justiça, e por isso meu ponto de vista está no cerne do problema. Quando apelo à justiça, coloco uma questão moral; quando formulo minha concepção de justiça, tento respondê-la" (Dworkin, 2002: 211).
} 


\section{Estado de Direito Humanitário e Justiça de Transição}

Com as reuniões do Conselho de Segurança da Organização das Nações Unidas realizadas depois de 24 de setembro de 2003, foi possível aprovar o Relatório S/2004/616, que estabeleceu, em nível supranacional, algumas linhas de base para a justiça de transição (Organização das Nações Unidas, 2012). As experiências mais recentes do Conselho de Segurança demonstravam que a consolidação da paz tanto nos períodos que se seguem logo após os conflitos, como também a longo prazo, apenas seria atingida com a criação de instituições legítimas para pôr fim a estes e a prevalência de uma administração legítima da justiça. Some-se a isto que uma proteção adequada de minorias somente ocorreria sob os auspícios do Estado de Direito. Definindo uma linguagem comum para o documento, o Secretário-Geral das Nações Unidas conceituou a justiça de transição como o conjunto de medidas e mecanismos associados à tentativa de uma sociedade de lidar com um legado de abusos em larga escala no passado, buscando assegurar legitimidade (accountability), justiça e reconciliação. Dentro de tais mecanismos, pode-se falar em julgamentos individuais, reparações, busca pela verdade, reformas institucionais e expurgos no serviço público.

É interessante observar que o documento toma como base normativa para tal recuperação do Estado de Direito a Carta das Nações Unidas, o Direito Internacional dos Direitos Humanos, o Direito Penal Internacional e o Direito Internacional dos Refugiados. Neste contexto, estariam incluídos padrões normativos internacionais adotados pela Organização das Nações Unidas. ${ }^{12}$ Destaque-se, também, que um dos

\footnotetext{
12 "These standards also set the normative boundaries of United Nations engagement, such that, for example, United Nations tribunals can never allow for capital punishment, United Nations-endorsed peace agreements can never promise amnesties for genocide, war crimes, crimes against humanity or gross violations of human rights, and, where we are mandated to undertake executive or judicial functions, United Nations-operated facilities must scrupulously
} 
tópicos ao qual se dedica o documento é o referente ao papel que julgamentos criminais podem desempenhar em contextos de transição. Além de demonstrar que as instituições de Estado de Direito aplicam-se também para os violadores de direitos humanos, eles trazem alguma satisfação para as vítimas em termos de justiça e de recuperação de sua dignidade. Outro contributo em termos de legitimidade diz respeito à confiança que os cidadãos podem depositar no sentido de que o Estado está comprometido com o cumprimento do direito estabelecido.

Este não seria o local adequado para se polemizar o conceito de Estado de Direito. Feita a advertência de que o mesmo possui interpretações contextuais que indicam caminhos bastante diferentes (L'État de Droit, Rechtstaat ou Estado de Derecho), a opção por tal terminologia não é feita sem a consciência de que é preciso interpretar a mesma de um modo mais incisivo para que ela possa abarcar o Direito Internacional dos Direitos Humanos e o Direito Humanitário. Essa não é nenhuma novidade, uma vez que tem havido uma enorme expansão da utilização do termo Estado de Direito, percorrendo caminhos às vezes não isentos de críticas. Ainda assim, é possível notar, em pensadores como Fuller e Dicey, que há elementos contidos no conceito que se referem preponderantemente a instituições jurídicas, ou seja, normas e práticas de Estado que indicam uma estrutura de uma ordem jurídica, como adverte Martin Krygier (2011).

Isso não seria suficiente, já que há algo relativo à propósitos quando se discute um conceito contestado como esse. Um fio condutor parece ser, segundo Krygier, o de que o Estado de Direito se apresenta como a instância de controle da arbitrariedade no manejo do poder, mas não apenas isto, que se some a tal o fato de que o direito é um empreendimento argumentativo e que, por isto mesmo, não pode permitir que aqueles submetidos à lei sejam silenciados ou ignorados na sua digna capacidade de se opor. 
Por um lado, há que se pensar também na possibilidade de um específico “Estado de Direito Transicional" (transitional rule of law). Torelly (2012: 140-141) destaca que o mesmo beberia nas seguintes fontes normativas: a) a experiência nacional prévia de um sistema jurídico, ainda que relacionada ao direito anterior ao regime de exceção; b) o direito comparado, em suas diversas e localizadas experiências; c) o Direito Internacional. É possível, somando-se a essa proposta, avançarmos ainda mais na busca de um maior fortalecimento do Direito Internacional dos Direitos Humanos.

Por outro lado, a opção por um Estado de Direito Humanitário é preferível a um "constitucionalismo" mundial. ${ }^{13}$ Ela é menos discutível e mais plausível, dado que permeada por uma inquestionável proteção pro homine. Como eixo teórico para um Estado de Direito Humanitário que lida com influxos supranacionais, transnacionais, internacionais e domésticos na construção da justiça de transição, mais adequada se mostra a proposta de Giacomo Marramao de pensar a conjuntura atual a partir de uma perspectiva "glocalizada" (Robertson in Featherstone, Slash e Robertson, 1995), em que problematizar uma esfera pública global significa lidar com a diferença que evita a uniformização ${ }^{14}$.

Nessa perspectiva, é possível construir uma noção de Estado de Direito Humanitário que é fruto de duas linhas. Em primeiro lugar, podemos falar de uma perspectiva internacionalista, que se alimenta da normativa do Direito Internacional dos Direitos Humanos e do Direito Internacional Humanitário, apresentando-se com a

\footnotetext{
${ }^{13}$ Em defesa desse constitucionalismo, cf. Habermas (2008: 444-455). Devo a advertência sobre esse texto e a proposta de Marramao que se segue a Marcelo Cattoni, liberando-o, obviamente, das conclusões por mim assumidas.

14 “[...] a questão é delinear uma política universalista da diferença traçando uma linha de demarcação dupla: por um lado, em relação à política universalista da identidade, cuja mais nobre expressão acontece no programa ético transcendental de Kant; por outro lado, no que toca à política anti-universalista das diferenças, que na América do Norte é levada a cabo pelos comunitaristas e na Europa pela etnopolítica dos diversos regionalismos e movimentos separatistas tipo Liga Norte. Claro que isto não é uma solução, mas mais... uma moral provisória" (Marramao in Cardoso, 2008: 72).
} 
atuação jurisdicional de tribunais supranacionais e regionais de direitos humanos, decorrente, principalmente, de agentes que atuam na esfera internacional independentemente da vontade estatal. É o que Ruti Teitel (2011) denominou de Humanity's Law: a fundamentação das decisões de diversos atores estatais passa se colocar sobre uma gama imensa de normas de Direito Internacional que têm em vista a proteção do indivíduo.

Em segundo lugar, há uma outra via de construção que bebe nas experiências internas de cada Estado, o que torna possível a emergência de identidades constitucionais próprias que fornecem elementos jurídicos, históricos e sociais capazes de impulsionar o Estado de Direito Humanitário como que "de dentro para fora". Nesse caso, falaríamos de uma perspectiva doméstica, mas não fechada em si própria, e sim ciente do que a normativa internacional exige de cada um dos Estados nacionais. Uma análise, no campo da justiça de transição, desse ponto de vista, está no trabalho de Naomi RohtArriaza (2005) sobre o chamado "efeito Pinochet": a justiça universal passa a agir de modo pulverizado em países como Espanha, Argentina, Alemanha, Itália, Bélgica, França, entre outros, como também um modelo a ser seguido em termos de proteção individual, sempre com recurso a normas do Direito Internacional dos Direitos Humanos.

Nenhuma dessas perspectivas exclui-se mutuamente. Mas é preciso apontar que há, sim, em eventual situação de conflito, uma preponderância do Direito Internacional dos Direitos Humanos. Sem que seja necessário supor uma superioridade hierárquica de todo o Direito Internacional, como em Hans Kelsen (1998), o que ocorre é que a justiça de transição permite ou, aliás, exige essa comunicação entre os diversos sistemas. Isto se torna evidente ao nos defrontarmos com a maneira como tratados, normas de jus cogens e o costume internacional passam a ser referenciados na ordem interna anterior, 
concomitante ou posteriormente a decisões de órgãos supranacionais de direitos humanos. Ou mesmo quando se pensa na forma como juízes e tribunais referendam outras decisões de tribunais estrangeiros. ${ }^{15}$

Não há, contudo, e é preciso frisar, elemento de maior destaque nesse campo do que o concernente aos crimes contra humanidade. Uma reconstrução desse conceito se faz necessária. Ela será fundamental por que também aqui estaremos a tratar de conceitos contestados ou em disputa. Além disto, ela é necessária por que toca exatamente em um ponto sensível da justiça de transição - e, principalmente, da justiça de transição brasileira - permitindo, uma vez mais, sua própria reinterpretação a exigir um reforço normativo na forma de lidar com tais crimes.

\section{Crimes contra a Humanidade ante o Estado de Direito Humanitário: Costumes Internacionais, Jus Cogens e Obrigações Erga Omnes}

Construída sob os auspícios do Tribunal de Nuremberg, a noção de crimes contra a humanidade quer evocar a lesividade provocada por atos que atentam contra o próprio sentido de humanidade do homem. ${ }^{16}$ Boa parte dos países aliados percebeu, durante a Segunda Guerra Mundial, que vários dos crimes praticados pelos nazistas não se dirigiam contra estrangeiros, mas, como é sabido, contra cidadãos da própria Alemanha;

\footnotetext{
${ }^{15}$ Para uma análise da forma como podem se enredar as decisões de diversos tribunais em diferentes níveis, cf. Neves (2009). Para uma análise específica dessas correlações no campo da justiça de transição, cf. Torelly in Meyer (2014: 479 e ss).

16 "Com efeito, a humanidade é que se instala no estatuto de vítima, uma "vítima absolutamente única, que escapa ao Direito comum, diante da qual devem apagar-se os direitos do homem incapazes de apreendê-la, [...] mas as consequências dessa inovação são tão dolorosas politicamente que ela se torna uma noção conjuntural". Por conseguinte, a grande dificuldade de falar em crime contra a humanidade, ao longo da história, decorre precisamente do fato de que ele pode corresponder ao tratamento desumano, por um Estado, de sua própria população, sobre seu próprio território, competência que outrora correspondia ao estrito domínio reservado dos Estados. O Acordo de Londres, que instituiu o Tribunal de Nuremberg, reverteu, já em 1945, o princípio da imunidade no que atine à responsabilidade individual dos violadores, ao possibilitar o julgamento de agentes públicos que atuaram odiosamente em nome do Estado e por meio de seu aparelho" (Ventura, 2011: 217).
} 
não haveria, desse modo, como puni-los ante do Direito Internacional vigente, assim como ante os costumes de guerra. A ideia de vários dos responsáveis pela elaboração do Estatuto do Tribunal Militar Internacional de Nuremberg foi a de enquadrar tais atos ao que seria semelhante ao crime internacional de "agressão". A seção 6 (c) do Estatuto acabou por tipificar o que seriam crimes contra a humanidade. ${ }^{17}$

Acquaviva (2011: 885) salienta que, ante o princípio da legalidade, o grande argumento sempre levantado a favor desta definição é o de que ela estaria ligada, naquele momento, aos crimes de jurisdição do Tribunal de Nuremberg. A confirmação jurídico-política destes crimes deu-se efetivamente com a aprovação da Resolução $n^{\circ}$ 3/1946 e da Resolução n 95 (I)/1946, pela Assembleia Geral das Nações Unidas, que confirmaram os princípios do Estatuto de Nuremberg e aqueles decorrentes das condenações no mesmo tribunal. Já a Resolução n 2.391/1968 foi responsável por instituir a Convenção sobre Imprescritibilidade dos Crimes de Guerra e dos Crimes contra a Humanidade: ela especifica que tal imprescritibilidade incide mesmo para crimes contra a humanidade praticados em tempos de paz e mesmo que a legislação interna de um Estado não os tipifique.

A ausência de adesão ao tratado internacional não importa para o reconhecimento de sua aplicação. E isto por duas razões. A primeira delas é a de que referida convenção, seguindo os passos de Nuremberg, apenas tornou explícita uma norma de jus cogens. No âmbito do Direito Internacional, o jus cogens atua como "fonte de direito", sendo mencionado pelo art. 53 da Convenção de Viena sobre o Direito dos Tratados $^{18}$, incorporada em nosso ordenamento jurídico pelo Decreto 7.030 de 14 de dezembro de 1999. Observe-se, contudo, que, mesmo antes da definitiva incorporação,

\footnotetext{
${ }^{17}$ Cf. http://avalon.law.yale.edu/imt/imtconst.asp\#sec6. Acesso 14 Janeiro 2015.

${ }^{18}$ Cf. http://www.planalto.gov.br/ccivil_03/_Ato2007-2010/2009/Decreto/D7030.htm. Acesso em 5 dezembro 2014.
}

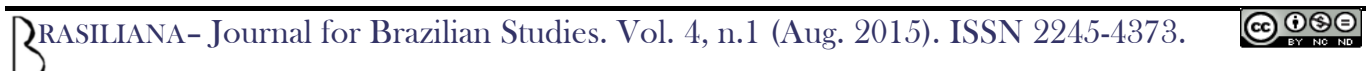


ela já era vista como obrigatória para todos os Estados, ainda que não tivessem os mesmos dado início ao processo de incorporação - tendo em vista seu caráter de Direito Internacional Geral.

Tomuschat (in Tomuschat e Thouvenin, 2006: 426) salienta que, em relação ao jus cogens, efetivamente há um conjunto de normas internacionais que detêm primazia (ele fala em normas "hierarquicamente" superiores) sobre outras normas de Direito Internacional e que não podem ser derrogadas pela vontade de dois ou mais Estados na medida em que permaneçam aceitas pela sociedade internacional. Este é o caminho construído pelos direitos humanos e que permite falar em um Estado de Direito Humanitário. Paul Tavernier (in Tomuschat e Thouvenin, 2006: 1) chega a falar em um processo gradativo de moralização do Direito Internacional, o que não nos parece ser o caso, já que o jus cogens está assentado em norma jurídica internacional.

É preciso considerar que a Corte Interamericana de Direitos Humanos já reconheceu o caráter impositivo das normas que punem os crimes contra a humanidade. O caso Almocinad Arellano y otros vs. Chile (Corte Interamericana de Direitos Humanos, Caso Almocinad Arellano vs. Chile, 2006) envolvia a prisão e execução extrajudicial de Luis Alfredo Almocinad Arellano, professor, militante do Partido Comunista chileno e sindicalista. Ele foi preso em sua casa no dia 16 de setembro de 1973, levado à porta da mesma e ali fuzilado à vista de seus familiares. O Decreto-Lei chileno 2.191/1978 buscou anistiar tais crimes; depois de diversas tentativas infrutíferas de medidas judiciais internas visando estabelecer responsabilidades, a família de Arellano levou o caso à Comissão Interamericana de Direitos Humanos que, posteriormente, provocou a Corte.

Em seu julgado, a Corte Inter-americana reconheceu que a noção de crimes contra a humanidade é anterior ao próprio julgamento de Nuremberg: ela remonta à Convenção de Haia sobre Leis e Costumes de Guerra Terrestre de 1907 (número IV) e a 
expressão foi cunhada por França, Reino Unido e Rússia para remeter ao massacre dos armênios na Turquia em 1915. Para que se configure um crime contra a humanidade, segundo a Corte, basta que um único ato seja praticado no contexto de um ataque generalizado e sistemático contra uma população civil. O mais importante foi assinalar que todos esses elementos preexistiam ao assassinato de Arellano.

Reconhecendo o conjunto de recentes medidas visando estabelecer responsabilizações por crimes contra a humanidade - por exemplo, as Resoluções 827 e 955 do Conselho de Segurança das Nações Unidas, os Estatutos dos Tribunais Penais Internacionais para a ex-Iugoslávia e Ruanda, assim como o Informe do Secretário-Geral das Nações Unidas que marca a impossibilidade de que acordos de paz estipulem anistias (S/2004/616, de 3 de agosto de 2004) - a Corte expressamente decidiu no sentido de abraçar o conceito internacional de crimes contra a humanidade, inclusive em relação à sua estrutura normativa (por exemplo, confirmando sua imprescritibilidade). ${ }^{19}$

A conclusão a partir desta e de outras decisões é semelhante para autores como Naomi Roht-Arriaza (1990: 449 ss): ela sustenta, desde o início da década de 1990, que há uma responsabilidade estatal internacional de investigação e persecução de desaparecimentos, esquadrões da morte e outras graves violações de direitos humanos praticadas por regimes opressores. Já naquele momento, ela destacava a incidência de um direito costumeiro internacional capaz de fundamentar um dever para com a verdade. Ele estaria assentado em: a) tratados internacionais que poderiam gerar obrigações mesmo para Estados não signatários, reconhecendo tais normas um direito a uma solução judicial (right to a remedy); b) práticas estatais, tais quais a persecução de

\footnotetext{
19 "Aún cuando Chile no ha ratificado dicha Convención, esta Corte considera que la imprescriptibilidad de los crímenes de lesa humanidad surge como categoría de norma de Derecho Internacional General (ius cogens), que no nace con tal Convención sino que está reconocida en ella. Consecuentemente, Chile no puede dejar de cumplir esta norma imperativa" (Corte Interamericana de Direitos Humanos, Caso Almocinad Arellano vs. Chile, 2006: 60-61).
} 
perpetradores, a formação de um direito doméstico conforme as normas internacionais de direitos humanos, as declarações de representantes governamentais, resoluções e declarações de organizações internacionais; e, c) a responsabilidade estatal pelos atos de seus agentes que consistam em graves violações de direitos humanos.

Em sentido equivalente, Cherif Bassiouni (1996a: 17) também defendera, em meados da década de 1990, uma estrutura normativa a partir da qual teríamos a formação de direitos e obrigações estatais concernentes à prática de crimes contra a humanidade. Tal estrutura tem caráter de norma imperativa de jus cogens e determina obrigações erga omnes. Especificamente, ela determinaria: ${ }^{20}$

a) a obrigação de persecução ou extradição;

b) fornecimento de assistência jurídica;

c) a eliminação de cláusulas de afastamento da norma penal (statutes of limitations, como as auto-anistias);

d) a eliminação de imunidades estatais;

e) e, adicionaríamos com Roht-Arriaza (1990: 506), a obrigação de inversão do ônus da prova em favor da vítima e em desfavor do Estado.

\section{Direito Costumeiro Internacional, Jus Cogens e Obrigações Erga Omnes na Ordem Jurídica Brasileira: a Inserção da Estrutura Normativa dos Crimes Contra a Humanidade no Contexto Brasileiro}

Deve-se demonstrar a incorporação da estrutura jurídica dos crimes contra a humanidade por meio do costume internacional que, de modo algum, conflita com a ordem jurídica doméstica, somando-se a essa normativa elementos de jus cogens e obrigações erga omnes. Como adverte Bryers (1999: 130), os elementos que formam o

${ }^{20}$ Cf. também, BASSIOUNI (1996b:63 e ss).

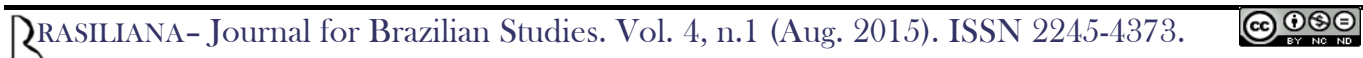


Direito Costumeiro Internacional são de duas ordens: a) a presença de uma consistente e geral prática estatal; b) a confirmação por parte dos Estados de que aquela prática está de acordo com o direito (opinio juris sive necessitatis).

Há um reconhecimento já efetivo dessa prática que caminha em um sentido sem retorno, passando a referida estrutura a ser parte de um direito doméstico "acostumado" (ainda que lentamente) a um genuíno Direito Internacional dos Direitos Humanos. Como bem observado por Marcelo D. Torelly (in Meyer: 2014: 479 ss), há uma progressiva incorporação de uma norma global de responsabilização individual nos diversos processos que Vicki Jackson (2009) classificou como de convergência, de articulação e de resistência. A questão é que se pode ir além, para perceber a introspecção de uma mais ampla estrutura normativa dos crimes contra a humanidade.

No caso brasileiro, é possível apontar as seguintes normas constitucionais como definidoras da incorporação da estrutura normativa dos crimes contra a humanidade como normas de jus cogens e obrigações erga omnes. ${ }^{21}$ Em primeiro lugar, há que se mencionar o art. $5^{\circ}$ da Constituição da República. Nos dispositivos concernentes ao acesso à justiça (inc. XXXV) e ao devido processo legal (inc. LIV) é possível verificar uma clara adesão ao direito à uma solução judicial (right to remedy) como norma determinante para a investigação e persecução de crimes contra a humanidade, nos termos sistematizados por Roht-Arriaza (1990: 449 ss). Já o direito à informação (inc. XXXIII) garante um direito à memória e à verdade e um dever de investigação por parte do Estado e de seus órgãos. Por sua vez, o $\S 2^{\circ}$ do mesmo art. $5^{\circ}$ irá expandir o campo de direitos fundamentais na perspectiva dos direitos humanos, de acordo com o que

\footnotetext{
${ }^{21}$ Observe-se, contudo, que essa incidência independe, a nosso ver, da conjugação entre normas constitucionais e normas de Direito Internacional dos Direitos Humanos, dada a incontornável força de tais determinações. Erga omnes obligations é um conceito construido pela Corte Internacional de Justiça no Barcelona Traction Case de 1970, no qual afirmou que eles "[...] are the concern of all states because of the importance of the obligations involved, which means all states can be held to have a legal interest in their protection". (De Wet in Shelton, 2013: 541-554).
} 
estabelece como uma não exaustão do rol de direitos, tanto por meio do sistema normativo instituído pela Constituição de 1988, quanto por conta de tratados internacionais.

É possível ir além e será o Ato das Disposições Constitucionais Transitórias que o fará. $\mathrm{O}$ art. $7^{\circ}$ do ADCT fixa que o Estado brasileiro propugnará pela formação de um tribunal internacional de direitos humanos, dispositivo que, no plano interno, torna imperiosas normas costumeiras, de jus cogens e obrigações erga omnes geradas pela atuação de órgãos como a Corte Interamericana de Direitos Humanos. Por fim, há que se mencionar que o art. $8^{\circ}$ do mesmo ADCT claramente marca o sentido de uma anistia que apenas é referente aos que foram "atingidos" por atos de exceção, institucionais ou complementares, não se podendo falar em qualquer tipo de óbice à incidência da estrutura dos crimes contra a humanidade no caso brasileiro, pelo contrário, o dispositivo estabelece uma exigência do seu cumprimento.

A prática estatal no Brasil também demonstra a adesão à mencionada estrutura, reforçando a incidência do costume internacional para regular os crimes contra a humanidade aqui praticados. Senão vejamos.

A Comissão de Anistia do Ministério da Justiça vem recorrentemente fazendo alusão às graves violações de direitos humanos praticadas por agentes públicos no período da ditadura como crimes contra a humanidade. No julgamento administrativo do requerimento do conhecido Cabo Anselmo, a Comissão de Anistia, além de destacar o sentido diverso da anistia estabelecida pelo art. $8^{\circ}$ do ADCT (em um claro rompimento com a concepção que se buscou afirmar com a Lei de Anistia de 1979), ostensivamente posicionou-se no sentido de que não se poderia conceder o pedido a alguém que corroborou a prática de crimes contra humanidade promovidos pelo Estado ditatorial, 
designando destacadamente as violações como sistemáticas (Brasil, Comissão de Anistia, Requerimento 2004.01.42025: 2012: 18).

Em cumprimento à decisão condenatória no Caso Gomes Lund (Corte Interamericana de Direitos Humanos, Caso Gomes Lund e Outros: 2010), o Ministério Público Federal, por meio da Resolução nº 1/2011 da 2a Câmara de Coordenação e Revisão Criminal, entendeu não haver colisão entre a decisão da corte regional de direitos humanos e a decisão do STF na ADPF 153/DF, que rejeitara o pleito do Conselho Federal da Ordem dos Advogados do Brasil para dar "interpretação conforme" à Lei de Anistia de 1979 (Brasil, Ministério Público Federal, Documento ${ }^{\circ}$ 1: 2011).22 Para o órgão, seriam diferentes os campos do controle de constitucionalidade e do controle de convencionalidade. Com isto, a noção de graves violações de direitos humanos, a nosso ver equivalente a de crimes contra a humanidade, ganhou densidade normativa na ordem jurídica brasileira.

Porém, os crimes contra a humanidade, nessa exata designação, teriam destaque com a propositura de ações penais relativas a crimes da ditadura perpetrados no início da década de 1970 (caso Rubens Paiva), e, daí, imprescritíveis, e após a anistia de 1979 (caso Riocentro). ${ }^{23}$ A noção de crimes contra a humanidade também seria invocada no caso que envolveu a morte e desaparecimento do opositor político Luiz Eduardo da Rocha Merlino (Brasil, Ministério Público Federal, Procedimento 1.34.001.007804/201157: 2014).

\footnotetext{
${ }^{22}$ Cf. Brasil, Supremo Tribunal Federal, Arguição de descumprimento de preceito fundamental 153 (2010); Meyer (2012); Meyer (2014); Weichert In: Meyer 2014: 563.

${ }^{23}$ Cf. Brasil, Ministério Público Federal, Procedimento 1.30.001.006990/2012-37 (2014); Brasil, Ministério Público Federal, Procedimento 1.30.001.0069906990/2012-37 (2014); Brasil, Ministério Público Federal, Procedimentos 1.30.001.005782/2012-11 e 1.30.011.001040/2011-16 (2014). O trabalho do MPF está sistematizado (com a clara alusão à tese) em BRASIL, Ministério Público Federal, Grupo de Trabalho justiça de transição: atividades desenvolvidas pelo Ministério Público Federal: 2011-2013 (2014).
} 
Também o Procurador-Geral da República mostrou claramente ter o Brasil sido incorporado ao desenho normativo dos crimes contra a humanidade, em duas ocasiões, pelo menos. Na primeira delas, ao apresentar parecer em relação ao pedido de extradição feito pela República Argentina em relação a Manuel Alfredo Montenegro, acusado de crimes de privação ilegítima de liberdade agravada com imposição de tortura durante a última ditadura argentina (Brasil, Ministério Público Federal, Parecer na Extradição 696: 2014). Ao discutir eventual impossibilidade da extradição em vista de incidência de norma anistiadora, o Procurador-Geral da República, Rodrigo Janot, destacou a nulidade das leis argentinas de "obediência devida" e "ponto final", reconhecida pela Suprema Corte Argentina em casos como Símon (Argentina, Corte Suprema de Justicia de la Nación, Causa $n^{\circ}$ 17.768: 2005). Também não haveria que se supor prescrição, dado que norma consuetudinária imperativa (jus cogens) sobre a imprescritibilidade teria sido apenas formalmente reconhecida com a adesão da Argentina à Convenção sobre a Imprescritibilidade dos Crimes de Guerra e dos Crimes Contra a Humanidade, prevalecendo previamente, como também assentara a mesma Suprema Corte em Arancibia Clavel (Argentina, Corte Suprema de Justicia de la Nación, Causa 259: 2005).

O mais importante, a fim de demonstrar a prática estatal capaz de fazer valer o costume internacional, foi o Procurador-Geral da República reconhecer que o destaque que deve ser dado é para a força costumeira e principiológica da imprescritibilidade de crimes contra a humanidade, o que também se aplica ao Brasil. Sua referência é o trabalho de Cherif Bassiouni. As palavras do Procurador-Geral da República merecem transcrição, pois demonstram o total desequilíbrio entre vítimas e perpetradores na prática de crimes contra a humanidade, fazendo merecer, no tratamento desses, peculiares formas de investigação e persecução: 
Na persecução de crimes contra a humanidade, em especial no contexto da passagem de um regime autoritário para a democracia constitucional, carece de sentido invocar o fundamento jurídico geral da prescrição, traduzido no brocardo dormientibus non sucurrit jus e no postulado da preservação da segurança jurídica. Nos regimes autoritários, os que querem o socorro do direito contra os crimes praticados pelos agentes respectivos não deixam de obtê-lo porque estão dormindo, e sim porque estão de olhos fechados, muitas vezes vendados; não deixam de obtê-lo porque estão em repouso, e sim porque estão paralisados, muitas vezes manietados. Falar em sanção contra a inércia quando não é possível sair dela constitui, no mínimo, grave contrassenso e, no limite, hipocrisia hermenêutica. Não há segurança jurídica a preservar quando a iniciativa se volta contra o que constituiu pilar de sustentação justamente de um dos aspectos autoritários de regime que, para se instaurar, pôs por terra, antes de tudo, a mesma segurança jurídica. (Brasil, Ministério Público Federal, Parecer na Extradição 696, 2014: 14)

A posição do Procurador-Geral da República ficaria ainda mais cristalina com o parecer apresentado na ADPF n 320, proposta pelo PSOL - Partido Socialismo e Liberdade. A ação foi proposta visando a que o STF declarasse que a Lei de Anistia de 1979 (Lei no 6.683/1979) não seria aplicada às graves violações de direitos humanos praticadas por agentes públicos contra os que, de modo efetivo ou suposto, teriam praticado crimes políticos durante a ditadura, bem como que a lei não seria aplicada a crimes continuados ou permanentes; além disso, que determinasse o STF o total cumprimento de todos os pontos decisórios constantes da decisão tomada pela Corte Interamericana 
de Direitos Humanos em Gomes Lund (Partido Socialismo e Liberdade - PSOL, Petição Inicial na ADPF 320, p. 2014). O Procurador-Geral da República claramente abraçou a tese encampada pelo Grupo de Justiça de Transição do Ministério Público Federal, integrado por membros da instituição que atuam neste campo.

Destacou o chefe do Ministério Público Federal que deveria prevalecer a distinção dos campos de controle de constitucionalidade e de controle de convencionalidade. Apontou também que o Estado brasileiro, soberanamente, submeteu-se à jurisdição da Corte Interamericana de Direitos Humanos, por meio do Decreto no 4.463/2002; e que, similar e previamente, aderiu à Convenção Americana de Direitos Humanos, via Decreto no 678/1992. Negar-se a cumprir a decisão tomada no Caso Gomes Lund exigiria prévia denúncia desses tratados, nos termos do art. 75 da Convenção Americana e do art. 44 (1) da Convenção de Viena sobre Direito dos Tratados (também incorporada pelo Decreto n $7.030 / 2009$ ) - o que, de mais a mais, implicaria em retrocesso inaceitável em matéria de direitos humanos. Como a própria jurisprudência do STF já reconhecera (Extradições no 974, 1.150 e 1.278), os crimes de desaparecimento forçado, como graves violações de direitos humanos, são permanentes, não havendo que se cogitar de prescrição ou anistia. Mas para além desses específicos crimes, deve prevalecer que as graves violações de direitos humanos são crimes contra a humanidade, portanto sujeitos a uma disciplina normativa de há muito firmada:

Instrumentos internacionais, a doutrina e a jurisprudência de tribunais de direitos humanos e cortes constitucionais de numerosos países reconhecem que delitos perpetrados por agentes estatais com grave violação a direitos fundamentais constituem crimes de lesahumanidade, não sujeitos à extinção de punibilidade por prescrição. Essas categorias jurídicas são plenamente compatíveis com o Direito 
nacional e devem permitir a persecução penal de crimes dessa natureza perpetrados no período do regime autoritário brasileiro pós-1964 (Brasil, Ministério Público Federal, Parecer na ADPF 320, 2014: 3).

A disciplina normativa elencada pelo Procurador-Geral da República merece aqui ser transcrita, dado que plenamente pertinente a evitar a alegação de retroatividade de na aplicação do conceito de crimes contra humanidade aos crimes da ditadura. Ele indica as seguintes normas de Direito Internacional que permitem identificar os crimes praticados pela ditadura brasileira em um contexto de um ataque generalizado ou sistemático contra a população civil: a) Carta do Tribunal Militar Internacional (1945); b) Lei do Conselho de Controle no 10 (1945); c) Princípios de Direito Internacional reconhecidos na Carta do Tribunal de Nuremberg e nos julgamentos do Tribunal, com comentários (International Law Commission, 1950); d) Relatório da Comissão de Direito Internacional da Organização das Nações Unidas (ONU) (1954); e) Resolução 2.184 (Assembleia Geral da ONU, 1966); f) Resolução 2.202 (Assembleia Geral da ONU, 1966); g) Resolução 2.338 (Assembleia Geral da ONU, 1967); h) Resolução 2583 (Assembleia Geral da ONU, 1969); i) Resolução 2.712 (Assembleia Geral da ONU, 1970); j) Resolução 2.840 (Assembleia Geral da ONU, 1971); k) Princípios de Cooperação Internacional na Identificação, Prisão, Extradição e Punição de Pessoas Condenadas por Crimes de Guerra e Crimes contra a Humanidade (Resolução 3.074 da Assembleia Geral da ONU, 1973); i) Convenção das Nações Unidas sobre a Imprescritibilidade de Crimes de Guerra e de Crimes contra a Humanidade, que, acrescente-se, incidiria como norma costumeira no caso brasileiro.

Destaque também é dado, no parecer do Procurador-Geral da República, para os casos da Corte Interamericana de Direitos Humanos e para tribunais estrangeiros. Algo fundamental, porque foca no modo como se lida judicialmente com tais crimes. E 
no caso brasileiro, a prática estatal ganha nova roupagem com recentes posicionamentos do próprio STF: ao aceitar a equiparação normativa dos crimes de desaparecimento forçado como sequestro no plano doméstico (art. 148 do Código Penal), a corte mostrase sensível para essa grave violação de direitos humanos. E a questão é que isto não foi feito uma vez, mas, ao menos, em três ocasiões. ${ }^{24}$

Mencione-se, como mais um indicativo da prática estatal, as decisões de recebimento das ações nos casos Rubens Paiva e Riocentro. Em relação ao primeiro caso, a decisão do Juiz Federal Caio Márcio Taranto estabeleceu que os crimes contra a humanidade da ditadura brasileira foram praticados no contexto de uma perseguição política. A ordem constitucional vigente à época já permitia o entendimento da incidência de princípios de Direito Internacional; para além disto, com o Decreto $\mathrm{n}^{\mathrm{o}}$ 10.719/1914, o Brasil ratificou a Convenção Concernente às Leis e Usos da Guerra Terrestre, firmada em Haia, em 1907. Some-se a isto a incidência do art. $6^{\mathbf{o}}$ do Estatuto do Tribunal de Nuremberg. A decisão ainda sustenta que a Convenção Interamericana para Prevenir e Punir a Tortura foi incorporada ao nosso ordenamento jurídico em 13 de novembro de 1989, por meio do Decreto no 98.386 , em data, pois, em que não teria ocorrido a prescrição da pretensão punitiva dos crimes relativos ao desaparecimento de Rubens Paiva; a partir de então, tal punibilidade tornou-se, por mais esse ângulo, imprescritível (e, portanto, um crime contra a humanidade) (Brasil, Justiça Federal, Recebimento de denúncia na ação criminal: 2014).

No caso Riocentro, a Juíza Federal Ana Paula Vieira de Carvalho aderiu à tese de que tais crimes se configuram como crimes contra a humanidade e são, portanto, imprescritíveis. Essa imprescritibilidade é um princípio geral de Direito Internacional,

${ }^{24}$ Cf. Brasil, Supremo Tribunal Federal, Extradição 974 (2009); Brasil, Supremo Tribunal Federal, Extradição $n$ 1.150 (2011); Brasil, Supremo Tribunal Federal, Extradição 1.278 (2012). 
tendo sido acolhido como costume pela prática dos Estados e por resoluções da Organização das Nações Unidas. Ela fez às Resoluções nํo 95, de 1946, e no 3.074, de 1973, da Assembleia Geral da ONU. Além disso, reforça a integração ao jus cogens desse preceito, ao destacar que, em 1914, o Brasil ratificou a Convenção Concernente às Leis e Usos da Guerra Terrestre, firmada em Haia em 1907, na qual reconhece "o caráter normativo dos princípios jus gentium preconizados pelos usos estabelecidos entre as nações civilizadas, pelas leis da humanidade e pelas exigências da consciência pública" (Brasil, Justiça Federal, Recebimento de denúncia na ação criminal no 2014.51.01.017766-5: 2014). ${ }^{25}$

\section{Conclusões}

Portanto, se é possível encontrar em ordens jurídicas comparadas o reconhecimento, como prática estatal, dos crimes contra a humanidade, dificilmente pode-se alegar que no Brasil a situação seja, hoje, diferente. Há um claro fluxo de incorporação dessa estrutura normativa e das consequências práticas que ela implica para a justiça de transição no Brasil. Como demonstrado no artigo, tem havido um aumento paulatino do número de instituições a consolidarem essa prática estatal: da Comissão de Anistia do Ministério da Justiça, passando pelo Ministério Público Federal, alcançando órgãos judiciais e a própria CNV.

A prática de crimes contra a humanidade, de modo sistemático e generalizado contra população brasileira, já foi reconhecida no sistema normativo interno. Juridicamente, esse reconhecimento já aparece com a Constituição de 1988 que, no art. $8^{\circ}$

\footnotetext{
${ }^{25}$ Registre que o Tribunal Regional Federal da $2^{\text {a }}$ Região manteve a decisão de primeira instância no julgamento do Habeas Corpus $n^{\circ}$ 104222-36.2014.4.02.0000 (Revista Consultor Jurídico: 2014) Ainda que a medica cautelar do Supremo Tribunal Federal na Reclamação $n^{\circ} 18.686$ interposta por um dos réus, tenha suspenso o processo, ela não discutiu, obviamente, o mérito e a qualificação dos crimes imputados ao acusado (Brasil, Supremo Tribunal Federal, Medida cautelar na reclamação no 18.686 : 2014).
}

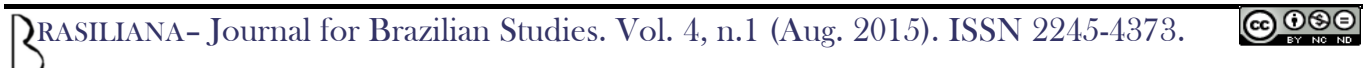


do Ato das Disposições Constitucionais Transitórias, consolida a situação jurídica do "anistiado político" e reconhece a lesão de direitos provocada por atos de exceção, institucionais e complementares. Também a Lei 9.140/1995, que reconhece como mortas as pessoas que exerceram atividades política ou foram acusadas de exercê-las, desaparecidas de 2 de setembro de 1961 a 5 de outubro de 1988, tendo sido detidas por agentes públicos, claramente confirmou a institucionalização de um política de repressão por parte do Estado brasileiro. $\mathrm{O}$ relatório final da $\mathrm{CNV}$ dá um passo significativo no processo transicional brasileiro, impulsionando a atividade persecutória do Ministério Público e permitindo que a "verdade" sirva de norte à "justiça".

\section{Referências}

Acquaviva, Guido. At the origins of crimes against humanity: clues to a proper understanding of the nullum crimen in the Nuremberg Judgement. Journal of International Criminal Justice, 9, 2011.

Argentina, Corte Suprema de Justicia de la Nación. A. 869. XXXVII. Arancibia Clavel, Enrique Lautaro s/ homicidio y associación ilícita. Causa $n^{\circ}$ 259. Fallos: 327:3312. Buenos Aires, 8 de março de 2005. Disponível em <www.csjn.gov.ar>. Acesso em 12 jul. 2012.

Argentina, Corte Suprema de Justicia de la Nación. S. 1767. XXXVIII. Símon, Julio Hector y otros s/ privación ilegítima de la libertad, etc. Causa $n^{\circ}$ 17.768. Fallos: 328:2056. Buenos Aires, 14 de junho de 2005. Disponível em <www.csjn.gov.ar>. Acesso em 12 jul. 2012.

Arthur, Paige. How "Transitions" Reshaped Human Rights: a Conceptual History of Transitional Justice. Human Rights Quaterly, 31, The Johns Hopkins University Press, 2009.

Bassiouni, Cherif. International Crimes: Jus Cogens and Obligatio Erga Omnes. Law and Contemporary Problems, vol. 59, nº 4, 1996 b. 
Bassiouni, Cherif. Searching for Peace and Achieving Justice: the Need for Accountability. Law and Contemporary Problems, vol. 59, no4, 1996 .

Brasil. Justiça Federal. 4⿳亠丷厂 Vara Criminal da Seção Judiciária do Rio de Janeiro/RJ. Recebimento de denúncia. Ação criminal nº 0023005-91.2014.4.025101. Juiz Federal Caio Márcio Gutterres Taranto. Disponível em < http://www.prrj.mpf.mp.br/institucional/crimes-da-ditadura/atuacao-1>. Rio de Janeiro, 26 de maio de 2014. Acesso em 15 jun. 2014.

. Justiça Federal. $6^{\text {a }}$ Vara Criminal da Seção Judiciária do Rio de Janeiro/RJ. Recebimento de denúncia. Ação criminal no 2014.51.01.017766-5. Juíza Federal Ana Paula Vieira de Carvalho. Disponível em <www.trf2.jus.br>. Rio de Janeiro, 13 de maio de 2014. Acesso em 15 jun. 2014.

- Ministério da Justiça. Comissão de Anistia. Requerimento de Anistia $n^{\underline{0}}$ 2004.01.42025. Requerente: José Anselmo dos Santos. Relator: Conselheiro Nilmário Miranda. Brasília, 22 de maio de 2012.

. Ministério Público Federal. 2ª Câmara de Coordenação e Revisão. Grupo de Trabalho justiça de transição: atividades desenvolvidas pelo Ministério Público Federal: 20112013. Coord. e org. Raquel Elias Ferreira Dodge. Disponível em < http://2ccr.pgr.mpf.mp.br/coordenacao/grupos-de-trabalho/justica-detransicao/relatorios-1/Relatorio\%20Justica\%20de\%20Transicao\%20-\%20Novo.pdf $>$. Acesso em 16 jun. 2014. Brasília: MPF/2a CCR, 2014.

. Ministério Público Federal. Procuradoria da República no Estado do Rio de Janeiro. Denúncia referente ao Procedimento de Investigação Criminal $n^{\underline{o}}$ 1.30.001.006990/2012-37. Disponível em: < http://www.prrj.mpf.mp.br/institucional/crimes-da-ditadura/atuacao-1 >. Acesso em 15 jun. 2014.

. Ministério Público Federal. Procuradoria da República no Estado do Rio de Janeiro. Denúncia referente ao Procedimento de Investigação Criminal $n^{\underline{o}}$ 1.30.001.0069906990/2012-37. Manifestação anexa. Disponível em: < http://www.prrj.mpf.mp.br/institucional/crimes-da-ditadura/atuacao-1 >. Acesso em 15 jun. 2014.

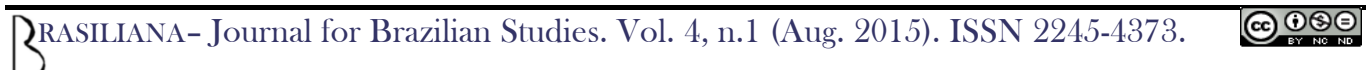


. Ministério Público Federal. Procuradoria da República no Estado do Rio de Janeiro. Denúncia referente as Procedimentos de Investigação Criminal $n^{\underline{0}}$ 1.30.001.005782/2012-11 e 1.30.011.001040/2011-16. Disponível em: < http://www.prrj.mpf.mp.br/institucional/crimes-da-ditadura/atuacao-1>. Acesso em 15 jun. 2014.

. Ministério Público Federal. Procuradoria da República no Estado de São Paulo. Denúncia referente ao Procedimento de Investigação Criminal no 1.34.001.007804/201157. Denúncia no 71284/2014. Disponível em <http://s.conjur.com.br/dl/denuncia-coronelustra.pdf>. Acesso em 21 out. 2014.

. Ministério Público Federal. Procuradoria-Geral da República. 2ª Câmara de Coordenação e Revisão. Documento $n^{\circ}$ 1/2011. Brasília/DF, 21 de março de 2011. Disponível em: <www.prr3.mpf.gov.br>. Acesso em 12 mar. 2012.

- Ministério Público Federal. Procuradoria-Geral da República. Parecer na Prisão preventiva para extradição $n^{0}$ 696. Requerente: República Argentina. Requerido: Manuel Alfredo Montenegro. Relator Ministro Gilmar Mendes. Disponível em < http://s.conjur.com.br/dl/extradicao-manuel-montenegro-parecer-pgr.pdf $>$. Acesso em 22 out. 2014.

- Ministério Público Federal. Procuradoria-Geral da República. Parecer na Arguição de Descumprimento de Preceito Fundamental no 320. Relator Ministro Luiz Fux. Disponível em <www.stf.jus.br>. Acesso em 22 out. 2014.

. Supremo Tribunal Federal. Arguição de descumprimento de preceito fundamental $n^{\circ}$ 153/DF. Arguente: Conselho Federal da Ordem dos Advogados do Brasil. Arguidos: Presidente da República e Congresso Nacional. Relator Ministro Luiz Fux. Brasília/DF: 29 de abril de 2010.2 Disponível em: $<$ http://www.stf.jus.br/portal/geral/verPdfPaginado.asp?id=330654\&tipo=TP\&descricao= ADPF\%2F153>. Acesso em 12 mar. 2011.

. Supremo Tribunal Federal. Extradição nº 974. Requerente: Governo da República Argentina. Extraditado: Manoel Cordeiro Piacentini. Relator Ministro Marco Aurélio. Relator para o acórdão Ministro Ricardo Lewandowski. Brasília/DF, 6 de agosto de 2009. Disponível em: < 
http://redir.stf.jus.br/paginadorpub/paginador.jsp?docTP=AC\&docID=606492>. Acesso em 12 mar. 2011.

. Supremo Tribunal Federal. Extradição $n^{\circ}$ 1.150. Requerente: Governo da Argentina. Requerido: Norberto Raul Tozzo. Relatora Ministra Cármen Lúcia. Brasília, 19 de maio de 2011. Disponível em <www.stf.jus.br>. Acesso em 23 mar. 2012.

- Supremo Tribunal Federal. Extradição $n^{\circ}$ 1.278. Requerente: Governo da Argentina. Requerido: Cláudio Vallejos. Relator Ministro Gilmar Mendes. Brasília, 18 de setembro de 2012. Disponível em <www.stf.jus.br>. Acesso em 22 out. 2014.

. Supremo Tribunal Federal. Medida cautelar na reclamação $n^{-}$18.686. Relator Ministro Teori Zavascki. Disponível em <www.stf.jus.br>. Acesso em 22 out. 2014.

. Supremo Tribunal Federal. Recurso extraordinário $n^{\circ}$ 466.343/SP. Recorrente: Banco Bradesco S/A. Recorrido: Luciano Cardoso Santos. Relator Ministro Cezar Peluso. Brasília, 3 de dezembro de 2008. Disponível em <www.stf.jus.br>. Acesso em 30 set. 2010.

BRYERS, Michael. Custom, Power and the Power of Rules: International Relations and Customary International Law. Cambridge: Cambridge University Press, 1999.

Comissão Nacional da Verdade. Relatório. Volume I. Brasília: CNV, 2014.

Corte Interamericana de Direitos Humanos. Caso Almocinad Arellano vs. Chile. San José, 26 de setembro de 2006. Disponível em < http://www.corteidh.or.cr/docs/casos/articulos/seriec_154_esp.pdf $>$. Acesso em 20 outubro 2014.

. Caso Gomes Lund e Outros ("Guerrilha do Araguaia") vs. Brasil. Sentença de 24 de novembro de 2010. Disponível em <www.corteidh.or.cr>. Acesso em 1 jan. 2011.

De Greiff, Pablo. Theorizing Transitional Justice. in Willinas, Melissa S. Nagy, Rosemary. Elster, Jon (orgs.). Transitional Justice. New York e Londres: New York University Press, 2012. 
De Wet, Erika. Jus Cogens and Obligations Erga Omnes. in Shelton, Dinah. The Oxford Handbook of International Human Rights Law. Oxford: Oxford University Press, 2013.

Dworkin, Ronald. Levando os Direitos a Sério. Trad. Nelson Boeira. São Paulo: Martins Fontes, 2002.

Habermas, Jürgen. The Constitucionalization of International Law and the Legitimation Problems of a Constitution for World Society. Constellations, volume 15, no 4, 2008.

Jackson, Vicki. Constitutional Engagement in a Transnational Era. New York: Oxford University Press, 2009.

Kelsen, Hans. Teoria Geral do Direito e do Estado. Trad. Luís Carlos Borges. São Paulo: Martins Fontes, 1998.

Krygier Martin. Four Puzzles about the Rule of Law: Why, What, Where? And Who Cares? In FLEMING, James E. (org.). Getting to the Rule of Law. New York e Londres: New York University Press, 2011.

Kritz, Neil (org.). Transitional Justice: How Emerging Democracies Reckon with Former Regimes. Volumes I, II, III e IV. Washington: United States Institute of Peace, 1995.

Lutz, Ellen. Transitional Justice: Lessons Learned and the Road Ahead. in RohtArriaza, Naomi. Mariezcurrena, Javier (coords.). Transitional Justice in the Twenty-First Century. Cambridge: Cambridge University Press, 2006.

Marramao, Giacomo. De Weltgeschichte à Modernidade-Mundo. O problema de uma esfera pública global. in Cardoso, Rui Mota (coord. geral). Política: Crítica do Contemporâneo. Conferências Internacionais Serralves 2007. Porto: Fundação Serralves, 2008.

Meyer, Emilio Peluso Neder. Ditadura e Responsabilização: Elementos para uma Justiça de Transição no Brasil. Belo Horizonte: Arraes Editores, 2012.

Meyer, Emilio Peluso Neder e Cattoni de Oliveira, Marcelo Andrade. Justiça de Transição nos 25 Anos da Constituição de 1988. Belo Horizonte: Initia Via, 2014. 
Neves, Marcelo. Transconstitucionalismo. São Paulo: WMF Martins Fontes, 2009.

O'Donnel, Guillermo. Schmitter, Philippe. Tentative Conclusions about Uncertain Democracies. Baltimore e Londres: The Johns Hopkins University Press, 1986.

Organizações das Nações Unidas. Conselho de Segurança. The rule of law and transicional justice in conflict and post-conflict societies: report of the Secretary-General. 23 de agosto de 2004. Disponível em <http://daccess-ddsny.un.org/doc/UNDOC/GEN/N04/395/29/PDF/N0439529.pdf?OpenElement>. Acesso em 26 mar. 2012.

Partido Socialismo e Liberdade - PSOL. Petição inicial na Arguição de descumprimento de preceito fundamental $n^{0}$ 320. Relator Ministro Luiz Fux. Disponível em <www.stf.jus.br $>$. Acesso em 20 out. 2014.

Pinto, Gabriel Rezende de Souza. Para a Democracia: Soberania, Transição e Rastro na Ação de Descumprimento de Preceito Fundamental n. 153. Dissertação de Mestrado. Brasília: UnB, 2013.

Pion-Berlin, David. To Prosecute or To Pardon: Human Rights Decisions in the Latin American Southern Cone. in Kritz, Neil (org.). Transitional Justice: How Emerging Democracies Reckon with Former Regimes. Volume I. Washington: United States Institute of Peace, 1995.

Poldevaart, Arie W. Black-Robed Justice. 1948.

Quinalha, Renan Honório. Justiça de transição: contornos do conceito. São Paulo: Outras Expressões, Dobra Universitária, 2013.

Revista Consultor Jurídico. Anos de chumbo: Ação contra acusados de matar Rubens Paiva deve seguir, diz TRF-2. 10 de setembro de 2014. Disponível em < http://www.conjur.com.br/2014-set-10/acao-acusados-matar-rubens-paiva-seguir-trf $>$. Acesso em 22 out. 2014.

Robertson, Roland. Glocalization: Time-Space and Homogeneity-Heterogeneity. in Featherstone, M. Lash, S. e Robertson, Roland (orgs.). Global Modernities. Londres: Sage, 1995. 
Roht-Arriaza, Naomi. State Responsibility to Investigate and Prosecute Grave Human Rights Violations in International Law. California Law Review, 78, 1990.

. The New Landscape of Transitional Justice. in Roht-Arriaza, Naomi. Mariezcurrena, Javier (coords.). Transitional Justice in the Twenty-First Century. Cambridge: Cambridge University Press, 2006.

. The Pinochet Effect: Transnational Justice in the Age of Human Rights. Philadelphia: University of Pennsylvania Press, 2005.

Rosenfeld, Michel. A identidade do sujeito constitucional e o Estado Democrático de Direito. Cadernos da Escola do Legislativo, vol. 7, no 12, p. 11-63, jan.-jun., Belo Horizonte, 2004.

Tavernier, Paul. L'identification des règles fondamentales - un problème résolu? in Tomuschat, Christian. e Thouvenin, Jean-Marc (eds). The fundamental rules of international legal order: jus cogens and obligations erga omnes. Leiden: Koninklijke Brill NV, 2006.

Teitel, Ruti. Humanity's Law. New York: Oxford University Press, 2011. . Transitional Justice. Oxford e New York: Oxford University Press, 2001. . Transitional Justice Genealogy. Harvard Human Rights Journal, 16, 2003.

Tomuschat, Christian. Reconceptualizing the debate on jus cogens and obligations erga omnes - concluding observations. in Tomuschat, Christian. e Thouvenin, Jean-Marc (eds). The fundamental rules of international legal order: jus cogens and obligations erga omnes. Leiden: Koninklijke Brill NV, 2006.

Torelly, Marcelo D. A Formação da Norma Global de Responsabilidade Individual: Mobilização Política Transnacional, Desenvolvimento Principiológico e Estruturação em Regras Internacionais e Domésticas. in Meyer, Emilio Peluso Neder e Cattoni de Oliveiar, Marcelo Andrade. Justiça de Transição nos 25 Anos da Constituição de 1988. Belo Horizonte: Initia Via, 2014. 
- Justiça de Transição e Estado Constitucional de Direito: perspectiva teóricocomparativa e análise do caso brasileiro. Belo Horizonte: Fórum, 2012.

Ventura, Deisy. A interpretação judicial da Lei de Anistia brasileira e o Direito Internacional. BRASIL. Comissão de Anistia. Ministério da Justiça. Revista anistia política e justiça de transição. N. 4 (jul./dez. 2010). Brasília: Ministério da Justiça, 2011.

Weichert, Marlon Alberto. Proteção penal contra violações aos direitos humanos. in Meyer, Emilio Peluso Neder. e Catonni de Oliveira, Marcelo Andrade. Justiça de Transição nos 25 Anos da Constituição de 1988. Belo Horizonte: Initia Via, 2014.

Zalaquett, José. Confronting Human Rights Violations Committed by Former Governments: Principles Applicable and Political Constraints. in Kritz, Neil (org.). Transitional Justice: How Emerging Democracies Reckon with Former Regimes. Volume I. Washington: United States Institute of Peace, 1995. 